Revista de Ensino em Artes, Moda e Design

Dossiê 6

A modelagem integrada ao projeto de Moda no âmbito do ensio

\title{
METODOLOGIAS COLABORATIVAS DO DESIGN PARA MODELAGEM PLANA DO VESTUÁRIO
}

\section{Collaborative design methodologies for clothing flat modeling}

\section{Metodologías de diseño colaborativo para el modelado plano de ropa}

\section{Élida Belquice de Araújo Santiago ${ }^{1}$}

Raquel Gomes Noronha²

Ana Lucia Alexandre de Oliveira Zandomeneghi ${ }^{3}$

\footnotetext{
${ }^{1}$ Mestranda pelo Programa de Pós-Graduação em Design da Universidade Federal do Maranhão (UFMA). Docente do quadro efetivo do Eixo de Produção Industrial do Instituto Federal do Piauí (IFPI- Piripiri). E mail: elidabelquice@gmail.com | Lattes: http://lattes.cnpq.br/6454581006921173| Orcid: https://orcid.org/0000-0002-0251-4166

${ }^{2}$ Doutora (PPCIS-UERJ, 2015) em Antropologia e mestre (PPGCSoc-UFMA, 2008). Docente do Programa de Pós-Graduação em Design da Universidade Federal do Maranhão (UFMA).E mail: Raquelnoronha79@gmail.com | Lattes: http://lattes. cnpq.br/4782161324909358 | Orcid: https://orcid.org/0000-0002-3753-5143

${ }^{3}$ Pós- Doutora em Engenharia e Gestão do conhecimento pela Universidade Federal de Santa Catarina (UFSC, 2012), Doutora e Mestre em Engenharia de Produção pela (UFSC, 1998 e 2005). Docente do Programa de Pós-Graduação em Design da Universidade Federal do Maranhão (UFMA). E mail: ana.zandomeneghi@ufma.com| Lattes: http://lattes.cnpq. br/146820404435056| Orcid: https://orcid.org/0000-0001-6140-8841
} 


\title{
Resumo
}

Este artigo reflete sobre a importância das metodologias colaborativas do design na construção de novas configurações para o ensino de modelagem plana do vestuário, entendendo que, por meios colaborativos, é possivel contribuir com atividades e solutos de diversos campos partindo de um novo olhar ao conceber conceitos e soluções formais. A metodologia utilizada nesta pesquisa seguiu os pressupostos da abordagem qualitativa, realizada por meio de estudo bibliográfico e Revisão Sistemática de Literatura. A partir dos levantamentos conceituais e experimentais de pesquisas realizadas sobre o ensino-aprendizagem de modelagem plana do vestuário, apresentamos formas de aplicação do design colaborativo e suas abordagens metodológicas para problemáticas levantadas nesse ensino. Os resultados evidenciaram que a partir do planejamento de uma metodologia colaborativa aplicada à modelagem plana do vestuário, é possivel a construção de projetos que, na prática, são mais concisos e próximos da realidade dos usuários, que nesta pesquisa inclui docentes e discentes dos cursos de design de moda e vestuário.

Palavras-chave: Design colaborativo; Modelagem plana do vestuário; Metodologia colaborativa.

\begin{abstract}
This article reflect about the importance of collaborative design methodologies in the construction of new configurations for the teaching of flat clothing modeling, understanding that, through collaborative means, it is possible to contribute with activities and solutions from different fields from a new perspective. When designing concepts and formal solutions, the methodology used in this research have followed the assumptions of the qualitative approach, carried out through bibliographic study and Systematic Literature Review. It has been based on conceptual and experimental surveys of research carried out teaching and learning about flat clothing modeling, we present ways of applying collaborative design and its methodological approaches to problems raised in this teaching. The results showed that, from the planning of a collaborative methodology applied to the flat modeling of clothing, it is possible to build projects that, in practice, are more concise and close to the reality of the users, in which this research includes teachers and students from the courses of fashion and clothing design.
\end{abstract}

Keywords: Collaborative design; Flat modeling of clothing; Collaborative methodology. 


\section{Resumen}

Este artículo refleja sobre la importancia de las metodologías de diseño colaborativo en la construcción de nuevas configuraciones para enseñar el modelado de ropa plana, entendiendo que, a través de medios colaborativos, es posible contribuir con actividades y soluciones de diferentes campos, comenzando desde una nueva perspectiva. al diseñar conceptos y soluciones formales. La metodología utilizada en esta investigación siguió los supuestos del enfoque cualitativo, realizado a través del estudio bibliográfico y la Revisión sistemática de la literatura. Con base en encuestas conceptuales y experimentales de investigación llevada a cabo sobre la enseñanza y el aprendizaje sobre el modelado de ropa plana, presentamos formas de aplicar el diseño colaborativo y sus enfoques metodológicos a los problemas planteados en esta enseñanza. Los resultados mostraron que, a partir de la planificación de una metodología colaborativa aplicada al modelado plano de la ropa, es posible construir proyectos que, en la práctica, sean más concisos y cercanos a la realidad de los usuarios, que en esta investigación incluye docentes y estudiantes de los cursos de El diseño de moda y vestimenta, esto ocurre, como resultado de la contribución colaborativa en el proceso. Presentando asi las metodologías colaborativas como un gran aliado para el papel del diseñador en los tiempos contemporáneos.

Palabras-clave: Diseño colaborativo; Modelado plano de ropa; Metodología colaborativa para el modelado de prendas planas.

\section{INTRODUÇÃO}

Dentro do campo de ensino de moda e vestuário, mas especificamente nas disciplinas de modelagem plana, podem-se identificar diversos problemas no que diz respeito ao ensino-aprendizagem. Silva e França (2018) afirmam que se percebe pouca capacidade de compreensão da execução dos moldes por parte dos alunos, que fazem com que a disciplina seja vista com um grau de complexidade elevado no que se refere à compreensão da execução dos moldes, o que causa insatisfação, tanto por parte dos alunos quanto por parte das professoras que a ministram. Este artigo tem como base dados, quatro pesquisas realizadas em cursos de moda e vestuário no Brasil citadas no Quadro 1 e explicadas no decorrer do texto, referentes ao ensino-aprendizagem da técnica de modelagem plana e a partir de lacunas identificadas nos seus resultados, fundamentaremos os caminhos percorridos por essa pesquisa.

Partindo do pressuposto de que o entendimento dos porquês e as dificuldades presentes nos contextos apresentados nas pesquisas realizadas sobre o ensino-aprendizagem de modelagem plana nos últimos anos, não se devem a ações individuais e solitárias, mas de construções coletivas de todos os autores envolvidos, exploram-se, neste trabalho, conceitos e aplicações de metodologias colaborativas do design, como métodos inovadores e efetivos dessa construção, por meio de conceitos e fundamentações para as dificuldades apontadas nas experiências levantadas.

Atualmente, passamos por um momento de transição de maneiras de agir ou 
maneiras de produzir as metodologias tradicionais, pois estas vem sendo substituídas por novas formas, a partir de abordagens colaborativas, nos levando a repensar um produto, não mais apenas como algo concebido por um designer solitário. Como afirma Botero (2003):

Hoje, experiências bem-sucedidas, que integram o design ao trabalho de um grupo diversificado de pessoas, e que se expandem para incluir usuários e outras partes interessadas relevantes, indicam que há muito que se agregar partindo desse objetivo. (BOTERO, 2003, p.13, tradução nossa).

Nesta abordagem, a adoção de metodologias colaborativas em diversos contextos relacionados à solução de problemas, concepção de produção ou de produtos, tende a trazer inúmeros benefícios a um projeto.

Dessa forma, a questão que orienta esse estudo e que será respondida é: como as metodologias colaborativas do design podem contribuir com a modelagem plana do vestuário?

O artigo está estruturado nos seguintes tópicos: o primeiro que apresenta os objetivos, justificativas e estrutura do artigo, por meio introdutório. O segundo que visa esclarecer pontos e dificuldades levantados em pesquisas que foram realizadas nos últimos anos sobre o ensino-aprendizagem de modelagem plana do vestuário por meio de uma revisão sistemática de literatura que aponta dados sobre o estado da arte de modelagem plana e de metodologias colaborativas a fim de, a partir dessa compreensão, fundamentar a proposta. O terceiro traz o método utilizado para a pesquisa. O quarto tópico apresenta conceitos de metodologias colaborativas, e a relação do design colaborativo e a modelagem plana do vestuário, sintetizando o levantamento e resultados dessa pesquisa, por meio de um Quadro que apontará resultados e suas aplicações e por fim os resultados e discussões gerados a partir dos levantamentos feitos.

A fim de responder ao que foi proposto, objetivou-se analisar pesquisas e contextos de modelagem plana do vestuário, para propor aplicações colaborativas às questões levantadas dentro de disciplinas de modelagem plana dos cursos de design de moda e vestuário, para promover, assim, uma reflexão sobre o estado da arte dessa abordagem.

\section{PROBLEMÁTICAS NO ENSINO DE MODELAGEM PLANA DO VESTUÁRIO}

A modelagem do vestuário, "consiste em uma técnica utilizada para representar, por meio de moldes, a forma das roupas" (BERG, 2017, p. 20). Para a contextualização desta técnica nesse estudo, o ponto de partida para compreendê-la foi subdividir em duas aplicações: uma como uma etapa de construção da peça do vestuário, desenvolvida dentro das indústrias para facilitação da confecção das peças em grande escala; e outra como disciplina no processo de ensino de moda. Como etapa no desenvolvimento de peças do vestuário, ela se apresenta como uma fase bastante importante, uma vez que a sua aplicabilidade define a qualidade final da peça confeccionada, exigindo do profissional um domínio e conhecimento da técnica, bem 
como uma responsabilidade no seu desenvolvimento. E outra como uma etapa de ensino, foco de aplicação deste artigo, sendo, pois, o momento de preparação dos alunos dentro dos cursos de formação técnica e de design de moda.

Atualmente existem duas técnicas de desenvolvimento da modelagem, a plana ou bidimensional, que pode ser desenvolvida de forma manual ou computadorizada; e a técnica tridimensional, que é desenvolvida sobre um corpo ou busto de forma manual. Essas técnicas estão diretamente associadas às formas pelas quais são desenvolvidas e os materiais utilizados na sua construção. A primeira, que é a modelagem plana, é conceituada por Borbas e Bruscagim (2007, p. 161) "A modelagem plana (bidimensional) é um trabalho de precisão que exige medidas e cálculo apurado, uso de proporção e habilidade para imaginar o efeito em três dimensões. Os moldes planos são criados a partir de um conjunto de medidas."

A modelagem plana manual é realizada sobre um plano, com a utilização de réguas específicas e esquadros, tabelas de medidas entre outros materiais. Já a modelagem plana computadorizada, necessita de um software específico no sistema CAD/ CAM para a sua realização. A segunda técnica, a tridimensional, também conhecida como draping ou moulage é desenvolvida diretamente sobre um corpo ou busto, no qual após posicionado o tecido e as marcações do modelo, ela passa a ser planificada para ajuste e confecção.

Como apontam pesquisas realizadas recentemente em relação ao ensino de modelagem plana, Araújo et al. (2019, p. 44) "observa-se que nem todo aluno tem identificação e facilidade de aprendizagem deste conteúdo". Também Filgueiras et al. (2016, p. 51) apontam que "existe a dificuldade que profissionais da moda/design têm de fazer modelagem". As autoras afirmam ainda que:

É importante que os profissionais envolvidos no ensino-aprendizagem de tais matérias, e que buscam a excelência na formação acadêmica e mercadológica de seus alunos, tanto quanto na sua própria formação metodológica, compreendam um pouco sobre os porquês das dificuldades no ensino deste conteúdo. (FILGUEIRAS et al., 2016, p. 44).

O Quadro 1 apresenta quatro pesquisas realizadas nos últimos anos em cursos de design de moda e vestuário, referentes aos parâmetros e pontos discutidos aqui.

Quadro 1: Pesquisas e problemas identificados no ensino-aprendizagem da modelagem plana do vestuário

\begin{tabular}{|c|l|}
\hline \multicolumn{1}{|c|}{ Pesquisa } & \multicolumn{1}{c|}{ Problemas Identificados } \\
\hline $\begin{array}{l}\text { Modelagem plana industrial do ves- } \\
\text { tuário: diretrizes para a indústria do ves- } \\
\text { tuário e o ensino-aprendizado da ergonomia, da antro- } \\
\text { MENEZES; SPAINE, 2010 }\end{array}$ & $\begin{array}{l}\text { Aplicaño e da preocupação com o corpo } \\
\text { usuário em todos os âmbitos de desen- } \\
\text { volvimento de um molde; } \\
\text { Definição e aplicações da geome- } \\
\text { tria antes do aprendizado do traçado do } \\
\text { molde; }\end{array}$ \\
\hline
\end{tabular}




\begin{tabular}{|c|c|}
\hline $\begin{array}{l}\text { MODPLAN: ensino e aprendizagem } \\
\text { de modelagem plana por meio de um re- } \\
\text { curso tecnológico } \\
\text { SILVA; FRANÇA, } 2018\end{array}$ & $\begin{array}{l}\text { Falta de conhecimentos prévios; } \\
\text { Falta de motivações; } \\
\text { Carga horária insuficiente; } \\
\text { Condições físicas de laboratórios; } \\
\text { uso de tecnologias; }\end{array}$ \\
\hline $\begin{array}{l}\text { A modelagem por trás dos moldes: } \\
\text { experiências em sala de aula. } \\
\text { L I M A; S I LVA; U C H Ô A; N O R O - } \\
\text { NHA,2019 }\end{array}$ & $\begin{array}{l}\text { Conhecimentos prévios sobre arit- } \\
\text { méticas; convenção de tabelas de medi- } \\
\text { das do corpo humano; } \\
\text { Capacidade de problematizar e in- } \\
\text { terpretar modelos; discrepâncias de en- } \\
\text { tendimentos dos roteiros; } \\
\quad \text { Interpretações variadas no passo a } \\
\text { passo; }\end{array}$ \\
\hline $\begin{array}{l}\text { Experimento metodológico para } \\
\text { o processo de ensino-aprendizagem da } \\
\text { modelagem plana feminina: práxis do- } \\
\text { cente x discente no curso de design-mo- } \\
\text { da- UFC } \\
\text { ARAÚJO; SOUZA; FILGUEIRAS, } 2019\end{array}$ & $\begin{array}{l}\text { Tomada das medidas e cálculos fei- } \\
\text { tos incorretamente; } \\
\text { Uso de materiais como réguas e es- } \\
\text { quadro; }\end{array}$ \\
\hline
\end{tabular}

O Quadro 1 apresenta o estado da arte deste campo de pesquisa, o que se tem detectado e tentado avançar dentro dos contextos de aplicação e ensino da técnica, e esses pontos servem de parâmetros para melhoramentos. Tecnicamente falando, tratam -se de conteúdos os quais são relacionados ao ensino e aparecem como barreiras na aprendizagem e domínio dos alunos. Assim, partindo das bases e conceitos colaborativos, seria possível compreender, discutir e encontrar caminhos para a aplicação dessas metodologias as questões levantadas.

O que se observa dentro dessas pesquisas realizadas é que elas detectam e apontam dificuldades dos alunos na aprendizagem da modelagem, por meio das experiências vivenciadas, mas, que, ainda é necessária uma atenção a forma na qual se discutirá a superação das dificuldades apontadas no Quadro 1. Pelas especificidades e momentos de aplicabilidade dos conteúdos apontados no decorrer do processo, sugere-se uma forma consistente de resolução para os apontamentos do quadro, por meio de objetos de aprendizagem que trabalhem os conteúdos específicos, considerando a produção destes objetos por meio de metodologias colaborativas, envolvendo todos os sujeitos do contexto, no caso docentes e discentes de cursos de moda e vestuário.

A respeito do ensino de modelagem, considera:

No ensino da modelagem plana do vestuário, existe muita dificuldade por parte dos alunos para a visão espacial, portanto, é um grande desafio para o 
professor conseguir fazer com que o aluno seja capaz de visualizar a modelagem planificada sobre um corpo tridimensional, ou fazê-lo conseguir entender como a união das partes de um plano pode formar um objeto com volumes idênticos ao do corpo. (IERVOLINO, 2015, p. 5).

Ainda segundo lervolino (2015), muitos alunos consideram o conteúdo de modelagem engessado no que se referem as regras matemáticas que parecem ser isentas de significação quando este conteúdo é passado de forma isolada das outras áreas do conhecimento. Nunes e Rocha (2018), afirmam que pouco se tem discutido sobre a qualidade e os impactos dos recursos didáticos no ensino-aprendizagem da modelagem do vestuário.

Para o ensino dessas técnicas em sala de aula, existem inúmeras metodologias disponíveis, e são objetos de estudo por pesquisadores para avanços e melhor aplicabilidade no seu ensino. A modelagem plana manual, escolhida para essa investigação, dentro dos estudos citados no Quadro 1, é apontada como um tabu em vários aspectos relacionados ao ensino.

A fim de complementar as afirmações, Crepaldi (2017, p. 12) afirma “É necessário gerar interesse nos discentes para a construção da Modelagem, para o pensamento de construção que vai além dos procedimentos mecânicos de reprodução de diagramas". Nesse contexto, essa busca por gerar esses interesses nos discentes, o docente deve buscar ferramentas que o auxiliem em suas práticas. Assim, surgem os objetos de aprendizagem que se apresentam como excelentes ferramentas a serem utilizadas na sala de aula a fim de combater essas sistemáticas mecânicas. Nesse sentido:

A possibilidade de testar diferentes caminhos, visualizar conceitos de diferentes pontos de vista, comprovar hipóteses, faz dos Objetos de Aprendizagem instrumentos poderosos para despertar novas ideias, relacionar conceitos, despertar a curiosidade e para resolver problemas. (SANTOS, 2013, p. 35).

Assim, entende-se que os objetos de aprendizagem são um excelente recurso dentro destas problemáticas. Para o entendimento dos problemas referentes ao estado da arte da utilização dos métodos colaborativos e objetos de aprendizagem como ferramenta para docentes no ensino de modelagem plana, a fundamentação e delimitação desta pesquisa, utilizou-se a RSL ou Revisão Sistemática da Literatura, que, segundo Obregon (2017, p.12), trata-se “[...] de um método científico sistemático que visa estabelecer as correlações entre os elementos sobre o tema, permitindo ao pesquisador delimitar o estudo tendo como âncora o estado da arte de pesquisas afins." Considerando o que afirma ainda Tranfield et al. (2003), pois por meio da RSL é possível se realizar uma pesquisa transparente e reprodutível, melhorando consideravelmente os resultados de uma revisão de literatura.

A RSL, com base nos protocolos sugeridos, tem como base palavras-chave que estabelecem relações entre as temáticas aqui sugeridas, a fim de compreender se em algum momento foram ou estão sendo realizadas pesquisas com elas, justificando, assim, a necessidade ou mesmo a experimentação desta relação entre metodologias colaborativas e a modelagem plana do vestuário.

O objetivo desta Revisão Sistemática da Literatura é responder à questão: Existem pesquisas e relações entre design colaborativo e modelagem plana do vestuário? 
A coleta dos estudos começou com o planejamento e a determinação de parâmetros de pesquisa nas bases de dados selecionadas, que foram o portal da CAPES e Web of Science, no qual elas foram selecionadas por atenderem aos pontos de exigência requeridos e pela confiabilidade e amplitude de dados. Os tipos de documentos analisados foram teses, dissertações e artigos nas línguas português e inglês, no período dos últimos 5 anos. Foram utilizados ainda critérios de inclusão e exclusão, considerando-se inclusos documentos que apresentem relação com a temática e que possivelmente responderiam à questão sugerida. E como critério de exclusão seria: arquivos repetidos, pesquisas duplicadas, pesquisas de acesso restrito, artigos que não tratem de disciplinas referentes à moda e ao vestuário, e artigos que não apontem dados relevantes acerca das temáticas principais.

As palavras-chave escolhidas para as buscas nas bases de dados foram: modelagem plana do vestuário, design colaborativo, moda, conceitos e aplicações e objetos de aprendizagem. Para o jogo de associação, utilizou-se o design colaborativo como central para relacionar com as demais. Segue o Quadro 2, que apresenta as associações realizadas com as palavras-chave definidas para a pesquisa.

Quadro 2: Palavras-chaves e associações utilizadas na pesquisa

\begin{tabular}{|c|c|c|}
\hline $\mathbf{P}$ & Português/CAPES & Inglês/Web of Science \\
\hline \#1 & $\begin{array}{l}\text { "Design Colaborativo" } \\
\text { AND conceitos e aplicações }\end{array}$ & $\begin{array}{l}\text { "Collaborative Design" AND Con- } \\
\text { cepts and Applications }\end{array}$ \\
\hline \#2 & “Design & "Collaborative Design" AND fashion \\
\hline \#3 & $\begin{array}{l}\text { "Design Colaborativo" } \\
\text { AND modelagem plana do ves- } \\
\text { tuário }\end{array}$ & $\begin{array}{l}\text { "Collaborative Design" AND Flat } \\
\text { Clothing Modeling }\end{array}$ \\
\hline \#4 & $\begin{array}{c}\text { "Design Colaborativo" } \\
\text { AND objetos de aprendizagem }\end{array}$ & $\begin{array}{l}\text { "Collaborative Design" AND lear- } \\
\text { ning objects }\end{array}$ \\
\hline
\end{tabular}

Fonte: Autoras (2020)

Na pesquisa feita nas bases de dados da CAPES e na Web of Science, foram identificados o total de 1199 trabalhos, considerando artigos, dissertações e teses. Após a triagem inicial, em que foram lidos os resumos e as considerações finais de cada trabalho, foram selecionados 16 trabalhos, compondo, assim, o conjunto de consideração inicial. Os textos foram lidos na íntegra, considerando os critérios de inclusão e exclusão. Foram excluídos 13 trabalhos que não apresentavam conteúdo relevante para a pesquisa, por apresentarem como foco conteúdos referentes a outros aspectos do design de moda e da modelagem em si ou de metodologias colaborativas, não tratando das metodologias de modelagem plana do vestuário e o ensino-aprendizagem da técnica. O conjunto de consideração final da revisão sistemática da literatura deste trabalho é composto por três trabalhos. A revisão gráfica de síntese, ilustrada na Figura 1, apresenta os resultados e sintetiza dados da RSL realizada. 


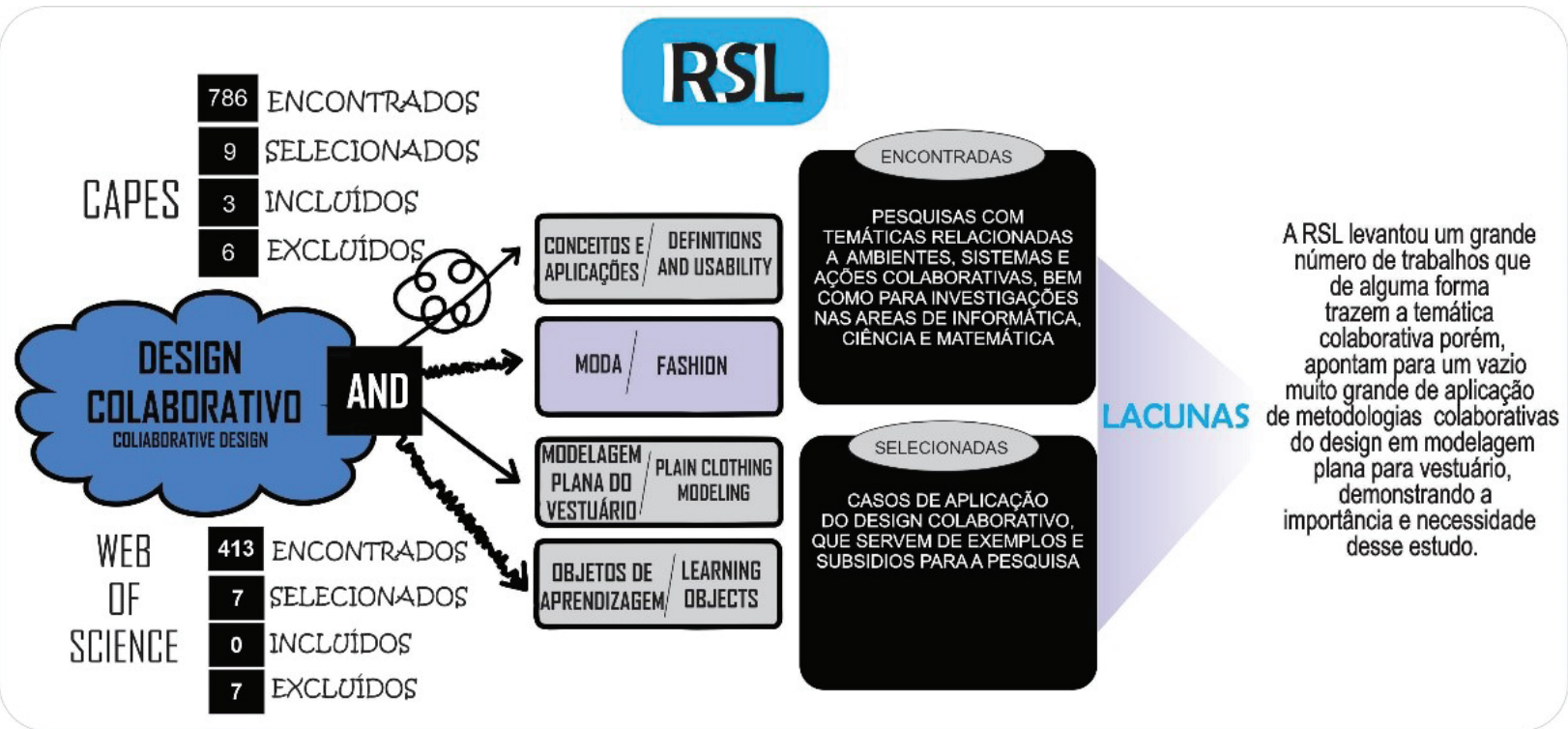

Fonte: Autoras (2020)

Dos três trabalhos selecionados na RSL, o primeiro apresenta contribuições teóricas do design colaborativo para os processos de desenvolvimento de jogos digitais. O resultado é a apresentação de uma seleção de teorias já consolidadas sobre ambos os temas. O segundo trabalho descreve o processo de produção de objetos de aprendizagem sob autoria dos alunos e identifica se e como esta experiência contribuiu para aquisição de competências a fim de construir colaborativamente o conhecimento por parte dos alunos. E o terceiro descreve um trabalho colaborativo como um caminho para transformar a prática, mostrando a experiência de um grupo de orientadoras educacionais.

\section{MÉTODO}

Os procedimentos metodológicos aplicados foram divididos em três etapas: a primeira consiste na pesquisa teórica referencial corresponde à validação do problema de pesquisa, por meio de uma revisão bibliográfica e sistemática de literatura, onde em consonância com Luna (1997), a revisão de literatura pode ser realizada com os seguintes objetivos: determinação do "estado da arte", o pesquisador procura mostrar através da literatura já publicada o que já sabe sobre o tema; quais as lacunas existentes; e onde se encontram os principais entraves teóricos ou metodológicos.

No segundo momento foi a contextualização das metodologias colaborativas para elaboração de uma proposta de modelo metodológico a partir da análise da revisão de literatura feita. E por fim o momento para as conclusões e reflexões sobre a importância e utilização das metodologias colaborativas para modelagem plana do vestuário.

Para tanto, como metodologia, utilizou-se a pesquisa exploratória-descritiva, com uma abordagem qualitativa. Quanto aos objetivos propostos nessa pesquisa, ela é de natureza básica, por objetivar gerar conhecimentos específicos, segundo Silva 
(2005, p. 20), objetiva gerar conhecimentos para aplicação prática e dirigidos à solução de problemas específicos. Assim essa pesquisa trata porém, de apenas um arranjo metodológico, no qual irá prosseguir a fim de aplicação dos métodos propostos, sendo realizada em uma próxima etapa nos cursos de design de moda e vestuário do Instituto Federal do Piauí, com docentes e discentes da área.

Toda a caracterização metodológica da pesquisa, baseada nesses moldes colaborativos, principalmente quanto aos seus objetivos e sobre uma lógica indutiva, e dentro de uma categorização de pesquisas em design, essa pesquisa pode ser ainda classificada como uma pesquisa-ação que, segundo Lewin (1946), trata-se de um método de pesquisa fenomenológico, de caráter exploratório, no qual o pesquisador tem envolvimento direto com o objeto de pesquisa, assumindo o papel de observador e de observado. A aplicação da pesquisa-ação será realizada de modo colaborativo, por meio de um grupo de colaboradores engajados com a ação, no qual o pesquisador também faz parte deste grupo e participa do processo de criação da mudança e de modo científico. Desta forma, a análise da investigação é feita a partir da contraposição entre a literatura, as reflexões do pesquisador e a autorreflexão coletiva.

\section{DESIGN COLABORATIVO E A MODELAGEM PLANA DO VESTUÁRIO}

O Design colaborativo pode ser considerado um contexto, uma abordagem, uma metodologia, um campo, depende da forma no qual é empregado. Existem diversos estudos a respeito desse conceito e que, por sua abrangência e importância nos resultados dos processos, pode assumir esses diversos papéis. Para essa fundamentação, utilizaremos o conceito proposto:

É um esforço recíproco entre pessoas de iguais ou diferentes áreas do conhecimento, separadas fisicamente ou não, com um objetivo comum de encontrar soluções que satisfaçam a todos os interessados. Isso pode acontecer compartilhando informações e responsabilidades, organizando tarefas e recursos, administrando múltiplas perspectivas e criando um entendimento compartilhado em um processo de design. A colaboração visa produzir um produto e ou informações com um certo grau de coordenação com as várias atividades implementadas. Esse processo dependente da relação entre os atores envolvidos, da confiança entre eles e da dedicação de cada parte. (FONTANA et al., 2012, p. 5).

As práticas colaborativas nos trazem novos conceitos e desafios metodológicos e projetuais, porém elas devem ser subsidiadas por bases conceituais que definam as atividades como colaborativas e não se confundam com participativas ou simplesmente reuniões coletivas. Para esse esclarecimento, considera-se importante e necessário caracterizar a prática pelas qualidades e níveis de intensidades da colaboração. Nesse sentido, Manzini (2017) afirma que organizações colaborativas podem ser distinguidas pelo grau de intensidade relacional que elas requerem. $O$ autor estabelece 4 dimensões que caracterizam os encontros colaborativos que, segundo ele, são "envolvimento ativo e envolvimento colaborativo, intensidade dos vínculos sociais e intensidade relacional" (MANZINI, 2017 p. 119). Afirmando que essas dimensões servem para os critérios de planejamento para os encontros colaborativos. 
Segundo Imbernón (2009; 2011; 2016), quando novos modelos relacionais e de trabalho fundados na colaboração são gerados no contexto da escola, possibilita-se um outro sentido para a identidade profissional individual e coletiva. Sugere-se aqui, porém, que o design colaborativo seja abordado como um processo que não deve permanecer somente de forma intuitiva em uma projetação, mas que deve acontecer efetivamente na construção direta do que será projetado. Spinuzzi (2005) enfatiza que existem diversos estudos relacionados a formas de participação em projetos, contudo, aparecem de forma imprecisa, dificilmente apresentando um desenho metodológico participativo. $O$ autor sugere etapas para o design participativo, enfatizando que desde os estudos iniciais era possível identificar que três estágios básicos estão presentes em quase todas as participações em pesquisa de design, sendo elas:

Etapa 1: Exploração inicial do trabalho, nesta fase os designers conhecem os usuários e familiarizam-se com as maneiras pelas quais trabalham juntos. Essa exploração inclui as tecnologias usadas, mas também inclui fluxo de trabalho e procedimentos, rotinas, trabalho em equipe e outros aspectos do trabalho. Etapa 2: Processos de descoberta, nesta fase, designers e usuários empregam várias técnicas para entender e priorizar a organização do trabalho e vislumbrar o futuro local de trabalho. Este estágio permite que designers e usuários esclareçam suas metas valores e estejam de acordo com o resultado desejado para o projeto. Esse estágio é frequentemente realizado no local ou em uma sala de conferências. Etapa 3: Prototipagem, nesta fase, designers e usuários moldam iterativamente artefatos tecnológicos, envolve um ou mais usuários. (SPINUZZI, 2005, p.167, tradução nossa)

A fim de contribuir com a efetividade da proposta e partindo dos pressupostos enfatizados por Spinuzzi, da importância de partir de um desenho metodológico conciso e condizente com a realidade da aplicação que será feita, adaptamos aos problemas detectados existentes no processo de ensino de modelagem plana do vestuário, a uma série de etapas de aplicação do design colaborativo a fim de enaltecer o trabalho colaborativo de docentes e discentes na superação desses problemas, por meio de trocas e construção de ferramentas de aprendizagem. Segue, na Figura 2 , o roteiro de etapas de um processo colaborativo. 


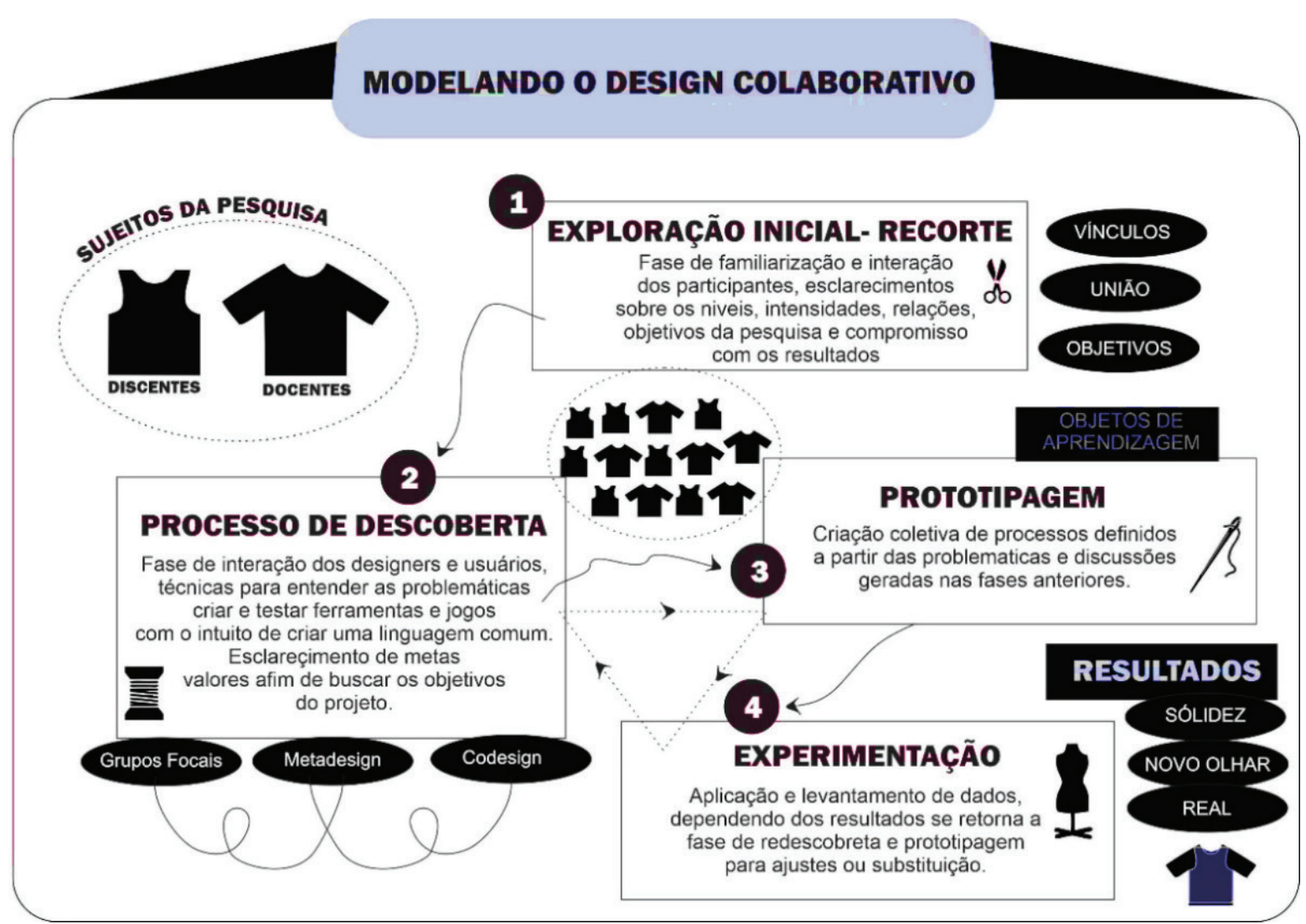

O roteiro aponta 4 etapas, o primeiro círculo do esquema está representando os sujeitos da pesquisa, composto por docentes e discentes dos cursos de design de moda e vestuário; o desenho de uma regata e uma camiseta, representando as diferentes experiências e papéis que cada um representa no processo, no qual um ensina e ou outro aprende. Assim, mesmo exercendo papéis diferentes durante o processo colaborativo, os dois se encontram no mesmo nível, inclusive papeis de designers e tem o mesmo objetivo, que será efetivado por meio das interações e trocas de experiências compartilhadas e geradas por esse novo grupo.

Passamos então para a primeira etapa, que chamaremos de exploração inicial ou recorte. Nesta etapa é a fase de familiarização e interação dos participantes, acontecendo esclarecimentos sobre os níveis, intensidades das relações, objetivos da pesquisa e compromisso com os resultados, sendo o momento de estabelecimento e fortalecimento de vínculos e a união da equipe.

A segunda etapa chamaremos de processo de descoberta, nesta fase acontece a interação dos designers e usuários, bem como trocas de experiências, devem ser utilizadas técnicas para entender as problemáticas para criar e testar ferramentas e jogos com o intuito de criar uma linguagem comum, fortalecendo o projeto por meios de metadesign.

O metadesign segundo Almeida (2014, p. 62) trata-se de "[...] novos paradigmas de processo projetual que se dedicam a superar metodológicos, entre eles as várias 
modalidades de co-criação". Desta forma ele serve no esclarecimento de metas e valores a fim de buscar os objetivos do projeto. Objetivos estes que são flexíveis e mutáveis durante todo o processo. Complementando as ações dessa fase:

\footnotetext{
Metadesign representa uma mudança cultural a partir do projeto como 'planejamento' para projetar como 'semeadura'. Através de práticas colaborativas e de transformação do design pode suportar novos modos de interação humana e sustentar uma expansão do processo criativo, novas formas de compreensão e planejamento com o objetivo de produzir mais sistemas abertos de interação em evolução. (GIACCARDI, 2005, 15).
}

A terceira etapa chamaremos de prototipagem, nesta fase é feita a criação coletiva de processos definidos a partir das problemáticas e discussões geradas nas fases anteriores, sugerindo-se a construção de objetos de aprendizagem para os conteúdos apresentados. E a quarta e última etapas consiste na aplicação e no levantamento de dados, dependendo dos resultados, retorna-se a fase de redescoberta e prototipagem para ajustes ou substituição.

Os processos colaborativos apresentam a peculiaridade da flexibilidade quanto a etapas e resultados, sendo isso que garante a efetividade dessas metodologias. Seguindo um direcionamento colaborativo ao final deste processo, tem-se um novo olhar dos sujeitos e das relações estabelecidas, da problemáticas e as soluções construídas, do papel de cada um e coletivo durante o processo, resultando num projeto sólido e real. Real, porque sendo construído pelos usuários juntamente com designers, se terá algo condizente com a realidade de quem vai utilizar o produto ou processo. E a solidez do processo se configura, segundo Kampa (2018, p. 20), a partir das ações realizadas em etapas, assim, são ações que valorizam e aperfeiçoam as relações das equipes. "Essas, ações são definidas como sendo as técnicas para o alcance do trabalho colaborativo." Construindo-se a partir desses processos uma relação dos colaboradores que passam a sentir sua participação ativa dentro do projeto.

\section{DISCUSSÕES E RESULTADOS}

A pesquisas no âmbito do ensino da modelagem plana no Brasil, realizadas em diversos contextos da disciplina dentro de cursos de moda, apontam para problemas no ensino-aprendizagem. A busca por novas configurações para este ensino, direcionou o nosso olhar para a necessidade de ações com a participação dos autores envolvidos, na construção de ferramentas por meio de etapas colaborativas. Assim, por meio de palavras chaves e a fim de responder a uma questão referente ao estado da arte, bem como a relação entre o design colaborativo e a modelagem plana, por meio da revisão sistemática de literatura foi possível entender os caminhos que precisam ser percorridos.

A análise e a discussão dos resultados apontam para a relevância dos conceitos e aplicações explorados nessa pesquisa, a fim de apresentar as contribuições das metodologias colaborativas para a modelagem plana do vestuário. As metodologias colaborativas do design são inovadoras e carregam ideias de uma nova forma de projetar. Essa nova forma transcende a uma visão isolada e um trabalho solitário de um 
designer, ou numa vaga visão de um problema, ela contextualiza diversas situações, escuta e é executada por um trabalho coletivo entre designers e usuários, por meio de ferramentas e conceitos de metadesign e formas dinâmicas, bem como estabelecimento de relações para definições de papéis e caracterizações dos usuários para o qual serão projetados.

Com sólidos caminhos, os quais se percorrem por meio de metodologias colaborativas, a fim de atendermos a questão dessa pesquisa, entendemos a necessidade de se seguir uma metodologia proposta por meio de etapas e atividades colaborativas a fim de atender as problemáticas existentes no âmbito das salas de aula dos cursos de design de moda, especificamente em disciplinas de modelagem plana. Nesse direcionamento, entende-se metodologia, como aponta Silva (2005, p. 9): "função de mostrar a você como andar no "caminho das pedras" da pesquisa, ajudá-lo a refletir e instigar um novo olhar sobre o mundo: um olhar curioso, indagador e criativo". Configurando nesse sentido, os caminhos que devem ser percorridos para que se alcancem as finalidades da pesquisa

\section{CONCLUSÃO}

Foram apresentadas as etapas essenciais para a fundamentação e a modelagem de uma metodologia colaborativa, e uma conceituação mínima sobre as etapas, visando proporcionar os primeiros passos para a comunidade acadêmica que pretende proceder com pesquisas que contribuam para o campo do ensino e, principalmente, que utilizem metodologias colaborativas. Concluiu-se que as metodologias por meio de etapas coerentes com o projeto a ser realizado, pode unir usuários para a construção de ferramentas a serem utilizados na solução de pontos e aspectos no ensino-aprendizagem de modelagem plana do vestuário, sendo essa uma importante contribuição para essas disciplinas ${ }^{1}$.

\section{REFERÊNCIAS}

ALMEIDA, Camila Caroline Teixeira de. O conceito de Metadesign. O Colloquium on Metadesign : Londres: Universidade Goldsmiths: SIGRADI, v.1, p. 62, dez. 2014. Disponível em: http://papers.cumincad.org/data/works/att/sigradi2014_200.content. pdf. Acesso em: 12 dez. 2019.

ARAÚJO, M. do S de; SOUZA, W. G. de; FILGUEIRAS, A. P. A. Experimento metodológico para o processo de ensino-aprendizagem da modelagem plana feminina: práxis docente $x$ discente no curso de design-moda- UFC. In: Ensinarmode.[s.l.: s.n.] v. 3, n. 2, jun./set. 2019. Disponível em: http://www.revistas.udesc.br/index.php/Ensinarmode/issue/view/Dossi\%C3\%AA\%204. Acesso em: 12 dez. 2019.

${ }^{1}$ Revisado por Jorgelene de Sousa Lima, e-mail: dilene.sousa@ifpi.edu.br; Mestre em Letras pela Universidade Federal do Piauí. 
BERG, Ana Lara Marchi. Técnicas de modelagem Plana feminina: construção de bases e volumes. São Paulo: Senac São Paulo, 2017.

BORBAS, M. C.; BRUSCAGIM, R. R. Modelagem plana e tridimensional - moulage - na indústria do vestuário. In.: Rev. Ciências Empresariais da UNIPAR, Umuarama: [s. n.], v. 8, n. 1 e 2, jan./dez. 2007. Disponível em: https://www.revistas.unipar.br/index.php/ empresarial/article/viewFile/2679/2043. Acesso em: 10 nov. 2019.

BOTERO, A.; KOMMONEN, K.-H.; OILINKI, I. \& KOSKIJOKI, M. Co-Designing Visions, Uses, and Applications. In: Electronic Proceedings of the 5th International Conference of the European Academy of Design. Techne- Desing Wisdom. Barcelona: European Academy of Design: Universidad de Barcelona, 2003. Disponível em: https://www.academia.edu/5847867/Expanding_Design_Space_s_._Design_in_ Communal_Endeavours. Acesso em: 08 out. 2019.

CREPALDI, Renata Nogueira. Ensino de modelagem: experiências e desafios em busca da formação do pensamento construtivo independente. Bauru, 2017. Disponível em: http://www.coloquiomoda.com.br/anais/Coloquio\%20de\%20Moda\%20 -\%202017/COM_ORAL/CO_2/CO_2_ENSINO_DE_MODELAGEM_EXPERIENCIAS.pdf. Acesso em: 30 nov.2019.

FILGUEIRAS, A. P. A.; ARAÚJO, M. do S de; SOUZA, W. G. de; CARVALHO, M. A. Reflexões sobre modelagem ergonômica no planejamento e elaboração de produtos do vestuário. In: 3 CONGRESSO INTERNACIONAL DE MODA E DESIGN-CIMODE. Buenos Aires: [s.n.], 2016. Disponível em: http://www.revistas.udesc.br/index.php/ Ensinarmode/article/view/14568/10074. Acesso em: 25 nov.2019.

FONTANA, Isabela Mantovani; HEEMANN, Adriano; GOMES FERREIRA, Marcelo Gitirana. Design Colaborativo: Fatores Críticos para o Sucesso do Co-design. In.: $4^{\circ}$ Congresso Sul Americano de Design de Interação. [S.l.: s. n.], 2012. Disponível em: https://www.academia.edu/9203614/Design_Colaborativo_Fatores_Cr\%C3\%ADticos_para_o_Sucesso_do_Co-design_Collaborative_Design_Crictical_Success_ Factor_for_Co-design_Fontana_Isabela_Mantovani_Universidade_Federal_do_Paran\%C3\%A1. Acesso em: 25 out.2019.

GIACCARDI, Elisa. "Metadesign as an Emergent Design Culture". In.: Leonardo, [S.l.: s. n.], v. 38, n.2, agost. 2005. Disponível em: https://www.researchgate.net/publication/249562528_Metadesign_as_an_Emergent_Design_Culture. Acesso em: 10 dez. 2019.

IERVOLINO, Fernanda. A tecnologia 3d como recurso didático para a aprendizagem da modelagem plana do vestuário. In.: Encontro nacional de pesquisadores em moda. [S.l.: s. n.], 2015. p 05-06. Disponível em: http://www.feevale.br/Comum/ midias/cd4c3a08-00cf-4b73-8979-b5334873a92e/A\%20TECNOLOGIA\%203D\%20 COMO\%20RECURSO\%20DID\%C3\%81TICO\%20PARA\%20A\%20APRENDIZAGEM\%20 
DA\%20MODELAGEM\%20PLANA\%20DO\%20VESTU\%C3\%81RIO.pdf. Acesso em: 11 dez. 2019.

IMBERNÓN, F. Formação permanente do professor. São Paulo: Cortez, 2009. 119 p.

IMBERNÓN, F. Formação continuada de professores. Porto Alegre: Artmed, 2011. $127 \mathrm{p}$.

IMBERNÓN, F. Qualidade do ensino e formação do professorado. São Paulo: Cortez, 2016. 229 p.

LIMA, Márcio Soares; SILVA, Lucilene Rodrigues da; UCHÔA, Jandeina Maria Barbosa;

NORONHA, Raquel Gomes. A modelagem por trás dos moldes: experiências em sala de aula. In.: Ensinarmode. [S.l.: s. n.], v. 3, n. 1, p.113 - 122, out/mai. 2019. Disponível em: http://www.revistas.udesc.br/index.php/Ensinarmode/article/view/14476/9741. Acesso em: 11 dez. 2019.

LUNA, Sergio Vasconcelos de. Planejamento de pesquisa: uma introdução. São Paulo: EDUC, 1997.

MENEZES, Marizilda dos Santos ; SPAINE, Patrícia Aparecida de Almeida. Modelagem Plana Industrial do Vestuário: diretrizes para a indústria do vestuário e o ensino-aprendizado. PROJÉTICA, LONDRINA, v. 1, n. 1, p. 82-100, dez. 2010. Disponível em: http://www.uel.br/revistas/uel/index.php/projetica/article/view/7737/6858. Acesso em: 11 dez. 2019.

NUNES, R de C; ROCHA, Maria Alice Vasconcelos. O ensino de modelagem do vestuário na perspectiva do Design da Informação. In.: Achiote revista eletrônica de moda. [S.l.: s. n.], v.6 . n. 2, p 12-17, dez. 2018. Disponível em: http://www.fumec.br/ revistas/achiote/article/view/6632/3396. Acesso em: 18 dez. 2019.

OBREGON, Rosane de Fatima Antunes. Perspectivas de pesquisa em design: estudos com base na Revisão Sistemática de Literatura. Erechim: Deviant, 2017.

KAMPA, Erick Renan. Processos colaborativos de design no desenvolvimento de jogos digitais. Curitiba: [s. n.], 2018. $110 \mathrm{f}$.

LEWIN K. Action research and minority problems. J Soc Issues. [S.l.: s. n.], v. 2, n. 34, 1946. p. 6.

SANTOS, Marcio Eugen Klingenschmid Lopes dos. Parâmetros de avaliação de objetos virtuais de aprendizagem. São Paulo; SP: [s.n], 2013.

SILVA, Edna Lúcia da. Metodologia da pesquisa e elaboração de dissertação. 4. ed. rev. atual. Florianópolis: UFSC, 2005. 
SILVA, Edna Maria dos Santos; FRANÇA, Sônia; Doutora. Modplan: ensino e aprendizagem de modelagem plana por meio de um recurso tecnológico. [S.l.: s. n.], 2018. Disponível em: http://www.coloquiomoda.com.br/anais/Coloquio. Acesso em: 07 Nov. 2019.

SPINUZZI, Clay. The Methodology of Participatory Design. Technical communcation. [S.l.: s. n.], v. 52, n. 2, maio 2005. Disponível em: https://www.researchgate.net/ publication/233564945_The_Methodology_of_Participatory_Design. Acesso em: 07 out. 2019.

TRANFIELD,D.;DENYER, D.; SMART,P. 'Towards a methodology for developing evidence-informed management knowledge by means of systematic review'. British Journal of Management. [S.l.: s. n.], v. 14, n. 207, 2003. Disponível em: https://www. cebma.org/wp-content/uploads/Tranfield-et-al-Towards-a-Methodology-for-Developing-Evidence-Informed-Management.pdf. Acesso em: 12 out. 2019.

Recebido em: 27/02/2020

Aceito em: $14 / 04 / 2020$ 